\title{
Seed Vigour Evaluation of Rocket (Eruca sativa Mill.) Seed Lots
}

\section{Eren OZDEN ${ }^{1 *}$, Nurcan MEMIS ${ }^{2}$, Zeynep GOKDAS ${ }^{2}$, Elif CATIKKAS ${ }^{3}$, Ibrahim DEMIR ${ }^{2}$}

\begin{abstract}
The work was carried out to test the seed vigour test to correlate seedling emergence potential of rocket seed lots in the field conditions. Standard laboratory germination percentages of the 12 seed lots were ranged between 87 and 93\%. Radicle emergence $(2 \mathrm{~mm})$ percentages after 18 (RE18h), 24 (RE24h), 36 (RE36h) and 48 (RE48h) during standard germination test, accelerated ageing test (AA, $\left.45^{\circ} \mathrm{C}, 100 \% \mathrm{RH}, 24 \mathrm{~h}, 48 \mathrm{~h}\right)$, electrical conductivity $\left(20^{\circ} \mathrm{C}, 40 \mathrm{ml}, 50\right.$ seeds $)$ of $8 \mathrm{~h}, 16 \mathrm{~h}$ and $24 \mathrm{~h}$ readings were used as vigour tests. Seeds were sown in two occasions in the field and vigour test results were correlated with seedling emergence percentages. Even though all seed vigour tests were significantly correlated with emergence at various levels EC24h and RE24h showed the highest correlation ( $<<0.001)$ with seedling emergence percentages in both sowing times. Correlation values were 0.824 and 0.844 in EC24h, 0.860 and 0.874 in RE24h.The lowest correlations were seen in standard laboratory germination test as 0.640 and $0.654(\mathrm{p}<0.05)$. Results indicated that EC24h and RE24h are practical and fast vigour tests that can be related to seedling emergence potential in rocket seed lots.
\end{abstract}

Keywords: Accelerated ageing test, electrical conductivity test, Eruca sativa, Radicle emergence test, Vigour test

\footnotetext{
${ }^{1}$ Eren ÖZDEN (Orcid ID: 0000-0001-7507-9815), Department of Horticulture, Faculty of Agriculture, Igdir University, Igdir, Turkey

${ }^{2}$ Nurcan MEMIŞ (Orcid ID: 0000-0002-8767-1186), Zeynep GÖKDAŞ (Orcid ID: 0000-0003-0788-1771), İbrahim DEMIR (Orcid ID: 0000-0003-4515-0689), Department of Horticulture, Faculty of Agriculture, Ankara University, Ankara, Turkey

${ }^{3}$ Elif ÇATIKKAŞ (Orcid ID: 0000-0002-0661-0219), Department of Medicinal and Aromatic Plants, Ermenek Vocational School, Karamanoglu Mehmet Bey University, Karaman, Turkey

*Sorumlu Yazar/Corresponding Author: Eren ÖZDEN, e-mail: eren.ozden@igdir.edu.tr
} 


\section{INTRODUCTION}

Sowing a vigorous seeds leads to rapid and uniform germination and optimal stand establishment resulting in rapid growth and yield (Marcos-Filho, 2015). Seed laboratory germination test is crucial part of seed quality but not always indicates the emergence percentages of any seed lot under adverse sowing conditions. Seed vigor is the part of the seed quality which determines the potential rapid and uniform emergence under a wide range of sowing conditions (Finch-Savage et al., 2010; ISTA 2017). Seed lots having high germination, but poor emergence are referred to as low vigour seeds, whereas those giving good emergence are termed high vigour seeds. Vigour tests have been proposed over many years. Tests that have been validated through the ISTA are electrical conductivity, accelerated ageing, controlled deterioration, radicle emergence and Tetrazolium staining (Powell and Mavi, 2016; ISTA, 2017). The controlled deterioration (CD) (Basak et al., 2006) and accelerated ageing (AA) (Hampton and TeKrony, 1995) tests have been successfully used to rank and predict relative field emergence potential of seed lots in various crops. Electrical conductivity test based on measuring of seed soak. Radicle emergence is rather recent vigour test that related to seedling emergence potential at various environmental conditions in a wide range of sowing conditions (Matthews and Powell, 2011; Demir et al., 2019; Ozden et al., 2019). Rocket is a leafy cool season vegetable crop. Germination of Rocket seed can be sporadic, but you should see most of the seeds germinating within a timeframe of 7 to 21 days. Rocket seed oil has a hypocholedterolemic effect; this may be due to the high percentage of unsaturated fatty acid (oleic $15.1 \%$, alpha linolenic acid $11.11 \%$, linoleic acid 8.3\%) (Abd El-Hamid, 1999). It is produced by seeds and sown in different times of the year in various environmental conditions in the Mediterranean region. Discriminating fast and well emerged seed lots has a value for predicting not only for estimation of stand establihment but also yield. Because yield in leafy vegetable species based on plant size which is under influenced by the emergence percentages and rate after sowing. The objective of the present research was to evaluate the accelertaed ageing (AA), Radicle emergence (RE) and electrical conductivity (EC) tests in rocket seeds, seeking to associate (i.e. predict) results with relative seedling emergence potential of seed lots in field sowing conditions.

\section{MATERIALS AND METHODS}

Twelve rocket (same cultivar) seed lots (Eruca sativa Mill.) were obtained from seed companies in 2017. Upon receipt, the seed moisture content was determined (ISTA, 2017) and packets were stored at $5{ }^{\circ} \mathrm{C}$ until use. Germination tests were carried out at $20^{\circ} \mathrm{C}$ in incubators, for which 50 seeds of each lot were placed between paper towels (Filtrak, Germany) $(20 \mathrm{~cm}$ x $20 \mathrm{~cm})$, wetted with $10 \mathrm{ml}$ of distilled water. The germination tests were conducted with four replicates of 50 seeds in the dark. Rolled paper towels were placed in plastic bags to prevent water loss. At the final count, 7 days after the commencement of the test, the seedlings were classified as either normal (healthy and well-developed plants) (ISTA, 2017). Normal seedling percentages in the final count were considered as standard germination (SG).

RE (radicle emergence, $2 \mathrm{~mm}$ ) was calculated in frequent counts of radicle emergence after 18 , 24, 36 and 48 hour during germination test. These counting times were determined in preliminary tests. Subsequently daily counts were carried out until 7 days. At the final count, 7 days after the commencement of the test, the seedlings were classified as either normal or abnormal (ISTA, 2017). Normal seedling percentages in the final count were considered as standard germination (SG).

For the accelerated aging test (AA), forty $\mathrm{ml}$ of distilled water was added to each plastic aging box $(11 \times 11 \times 4 \mathrm{~cm})$ and 200 seeds were placed on a monolayer cheese cloth placed on the wire mesh tray $(10 \times 10 \times 3 \mathrm{~cm})$ inside the box (Hampton and TeKrony, 1995). Seeds were aged at $45{ }^{\circ} \mathrm{C}$ for 24 and $48 \mathrm{~h}$. 
Seeds were dried on laboratory bench for about 3 hours. The standard germination test, four replicates of 50 seeds was then conducted, using normal seedling development for assessment (ISTA, 2017).

In electrical conductivity measurements, two replicates of 50 seeds of were weighed and soaked in $40 \mathrm{ml}$ distilled water for $24 \mathrm{~h}$ at $20^{\circ} \mathrm{C}$ in the dark. EC was measured at 8,16 and $24 \mathrm{~h}$ in rocket seeds. The electrical conductivity of seed soak water was measured using a conductivity meter (Schott-Gerate $\mathrm{GmbH}$, Hofheim) and expressed as $\mu \mathrm{S} \mathrm{cm}^{-1} \mathrm{~g}^{-1}$.

For the field emergence test (FE), seeds (four replicates of 100 seeds / lot) were sown $2 \mathrm{~cm}$ deep in the experimental field of the Department of Horticulture, Faculty of Agriculture, University of Ankara/Turkey, on 20 September 2017 (1. sowing) and 9 October in 2017 (2. sowing). The soil was a sandy loam (pH: $7.57, \mathrm{~N}: 0.09, \mathrm{P}_{2} \mathrm{O}_{5}: 5.5 \%, \mathrm{~K}: 0.16 \%$, Na: $0.41 \%$, Ca: $6.7 \%$, organic matter: $1.1 \%$ ). Daily minimum and maximum soil temperatures were recorded throughout both sowings and varied between 7 and $29^{\circ} \mathrm{C}$. The number of seedlings emerged assessed to have occurred when the cotyledons had unfolded above the surface was counted daily until 30 days after sowing.

Statistical analysis was conducted using the Statistical Package for Social Sciences (SPSS) by using analyses of variance. Mean separation was made at the $5 \%$ level by the Duncan multiple range test. Correlation coefficients (r) of vigor tests with seedling emergence performance in controlled room and field conditions were also calculated.

\section{RESULTS AND DISCUSSION}

The germination of seeds purchased from retailers ranged from 87 to $93 \%$ normal seedling percentages. Seven lots out of 12 ranged above 90\%, 5 lies between 87 and 90\%. All seed lots were above the required standard germination percentage level $(75 \%)$ in commerce.

Radicle emergence counts were ranged between 23 and 89\% at RE18h, 39 and 93\% at RE24h, 67 and $94 \%$ at RE36h, 75 and $95 \%$ at RE48h (Table 1). Lot 1 was significantly different than the rest of the lots in the first three counts ( $\mathrm{p}<0.05$ ). This lot reached to $89 \% \mathrm{RE}$ value within 18 hours of germination. The weakest lots (Lots 11 and 12) had 23 and 26\% RE values in 18 hours. The large differences in $\mathrm{RE} 18 \mathrm{~h}$ among the lots indicate that the germination time as an indicator of seed vigor varies among the lots.

Table 1. Standard germination (normal germination), radicle emergence percentages of 18, 24, 36 and 48 hours after germination, of 12 commercially available rocket seed lots. Means with different letters in the same column denote significant difference at $5 \%$ level.

\begin{tabular}{lccccc}
\hline & \multicolumn{5}{c}{ Radicle Emergence (RE) \% } \\
\cline { 2 - 6 } Seed lot & Standard germination test (SG) & RE18h & RE24h & RE36h & RE48h \\
\hline 1 & $93 \mathrm{a}$ & $89 \mathrm{a}$ & $93 \mathrm{a}$ & $94 \mathrm{a}$ & $95 \mathrm{a}$ \\
2 & $91 \mathrm{abc}$ & $68 \mathrm{~b}$ & $86 \mathrm{~b}$ & $91 \mathrm{~b}$ & $94 \mathrm{ab}$ \\
3 & $93 \mathrm{a}$ & $59 \mathrm{c}$ & $79 \mathrm{c}$ & $90 \mathrm{~b}$ & $91 \mathrm{c}$ \\
4 & $91 \mathrm{abc}$ & $46 \mathrm{~d}$ & $79 \mathrm{c}$ & $89 \mathrm{~b}$ & $92 \mathrm{bc}$ \\
5 & $92 \mathrm{ab}$ & $43 \mathrm{e}$ & $72 \mathrm{~d}$ & $83 \mathrm{c}$ & $88 \mathrm{~d}$ \\
6 & $90 \mathrm{bcd}$ & $39 \mathrm{f}$ & $79 \mathrm{c}$ & $84 \mathrm{c}$ & $92 \mathrm{bc}$ \\
7 & $88 \mathrm{de}$ & $38 \mathrm{f}$ & $62 \mathrm{f}$ & $80 \mathrm{~d}$ & $83 \mathrm{f}$ \\
8 & $89 \mathrm{cde}$ & $48 \mathrm{~d}$ & $66 \mathrm{e}$ & $82 \mathrm{~cd}$ & $86 \mathrm{e}$ \\
9 & $87 \mathrm{e}$ & $34 \mathrm{~g}$ & $59 \mathrm{~g}$ & $82 \mathrm{~cd}$ & $83 \mathrm{f}$ \\
10 & $90 \mathrm{bcd}$ & $27 \mathrm{~h}$ & $49 \mathrm{~h}$ & $73 \mathrm{e}$ & $80 \mathrm{~g}$ \\
11 & $88 \mathrm{de}$ & $23 \mathrm{i}$ & $39 \mathrm{i}$ & $71 \mathrm{e}$ & $78 \mathrm{~h}$ \\
12 & $88 \mathrm{de}$ & $26 \mathrm{~h}$ & $48 \mathrm{~h}$ & $67 \mathrm{f}$ & $75 \mathrm{i}$ \\
\hline Range & $87-93$ & $23-89$ & $39-93$ & $67-94$ & $75-95$ \\
\hline
\end{tabular}


When seed lots were subjected to accelerated ageing (AA) at $45{ }^{\circ} \mathrm{C}$ for $24 \mathrm{~h}$ and $48 \mathrm{~h}$ normal seedling germination fell. The extent of the fall was greater at $48 \mathrm{~h}$ than $24 \mathrm{~h}$ and varied among the lots (Table 2). Naturally longer ageing period extends the ageing level and decreased the potential normal germination percentages in all seed lots. But the differences among the lots in response to ageing are indicative of vigour differences resulting from prior ageing of seeds before the test. Fast decline in normal germination percentages after AA in lots 9 and 12 illustrated that these lots are of low vigourous.

Electrical conductivity readings ranged between 131 and $236 \mu \mathrm{S} \mathrm{cm}^{-1} \mathrm{~g}^{-1}$ at $8 \mathrm{~h}$ (EC8h), 154 and $307 \mu \mathrm{S} \mathrm{cm}^{-1} \mathrm{~g}^{-1}$ at $16 \mathrm{~h}, 206$ and $387 \mu \mathrm{S} \mathrm{cm}^{-1} \mathrm{~g}^{-1}$ at $24 \mathrm{~h}$ (Table 2). EC values gradually increased by the extending soaking time. However, high vigorous lots like lot 1 leached less than those low vigorous ones such as lots 11 and 12. EC value changed from $131 \mu \mathrm{S} \mathrm{cm}^{-1} \mathrm{~g}^{-1}$ at $8 \mathrm{~h}$ to $206 \mu \mathrm{S} \mathrm{cm}^{-1} \mathrm{~g}^{-1}$ at $24 \mathrm{~h}$ in lot 1 , these values were from 236 to $387 \mu \mathrm{S} \mathrm{cm}^{-1} \mathrm{~g}^{-1}$ in lot 12 . The differences between two readings were 75 and $151 \mu \mathrm{S} \mathrm{cm}^{-1} \mathrm{~g}^{-1}$ in lots 1 and 12 , respectively.

Table 2. Changes in AA test (AA24 and AA48h), EC after 8 (EC8h), 16 (EC16), 24 hours (EC24h) in 12 rocket seed lots. Means with different letters in the same column denote significant difference at $5 \%$ level.

\begin{tabular}{lccccc}
\hline Seed lot & AA24h & AA48h & EC8h & EC16h & EC24h \\
\hline 1 & $90 \mathrm{a}$ & $76 \mathrm{a}$ & $131 \mathrm{a}$ & $154 \mathrm{a}$ & $206 \mathrm{a}$ \\
2 & $87 \mathrm{bc}$ & $70 \mathrm{c}$ & $135 \mathrm{a}$ & $177 \mathrm{bc}$ & $218 \mathrm{~b}$ \\
3 & $86 \mathrm{bc}$ & $73 \mathrm{~b}$ & $139 \mathrm{a}$ & $165 \mathrm{ab}$ & $222 \mathrm{bc}$ \\
4 & $88 \mathrm{ab}$ & $70 \mathrm{c}$ & $133 \mathrm{a}$ & $184 \mathrm{c}$ & $233 \mathrm{~cd}$ \\
5 & $85 \mathrm{c}$ & $73 \mathrm{~b}$ & $140 \mathrm{a}$ & $183 \mathrm{c}$ & $238 \mathrm{de}$ \\
6 & $81 \mathrm{~d}$ & $62 \mathrm{de}$ & $175 \mathrm{~b}$ & $207 \mathrm{~d}$ & $250 \mathrm{e}$ \\
7 & $79 \mathrm{~d}$ & $60 \mathrm{e}$ & $190 \mathrm{c}$ & $239 \mathrm{ef}$ & $244 \mathrm{de}$ \\
8 & $75 \mathrm{e}$ & $64 \mathrm{~d}$ & $206 \mathrm{~d}$ & $250 \mathrm{fg}$ & $272 \mathrm{f}$ \\
9 & $69 \mathrm{f}$ & $56 \mathrm{f}$ & $198 \mathrm{~cd}$ & $235 \mathrm{e}$ & $273 \mathrm{f}$ \\
10 & $63 \mathrm{~h}$ & $56 \mathrm{f}$ & $203 \mathrm{~cd}$ & $270 \mathrm{~h}$ & $367 \mathrm{~h}$ \\
11 & $67 \mathrm{fg}$ & $50 \mathrm{~g}$ & $212 \mathrm{~d}$ & $260 \mathrm{gh}$ & $327 \mathrm{~g}$ \\
12 & $65 \mathrm{gh}$ & $49 \mathrm{~g}$ & $236 \mathrm{e}$ & $307 \mathrm{i}$ & $387 \mathrm{i}$ \\
\hline Range & $63-90$ & $49-76$ & $131-235$ & $154-306$ & $206-387$ \\
\hline
\end{tabular}

Seedling emergence percentages in the field sowings were ranged between 60 and $89 \%$ in the first, 56 and $81 \%$ in the second sowing (Table 3 ). The highest and significantly different $(\mathrm{p}<0.05)$ emergence compared to the rest of the lots in both sowings were shown by lot 1 as 89 and $81 \%$. The lowest values were shown by lot 12 as 60 and $56 \%$. Values of emergence percentages were quite similar between the sowing times. The largest difference was observed in lot 1 as $8 \%$ in favor of first sowing. In the rest of the lots differences in emergence percentages of first and second sowings were varied among the lots.

Correlation coefficients between seed vigour tests and field emergence in two sowings indicated several close associations (Table 4). The strongest correlations were obtained in EC24h and RE24h. Both vigour tests correlated seedling emergence percentages in two sowings as $p=0.001$ level. The correlations in remaining seed vigour tests were relatively lower levels (Table 4). The lowest correlation level was observed in standard germination test $(\mathrm{SG})$ with $\mathrm{p}<0.05$. 
Table 3. Changes in field emergence percentages in two sowings of 12 rocket seed lots. Means with different letters in the same column denote significant difference at $5 \%$ level.

\begin{tabular}{lcc}
\hline \multirow{2}{*}{ Seed lot } & \multicolumn{2}{c}{ Field Emergence (\%) } \\
\cline { 2 - 3 } & 1. Sowing & 2. Sowing \\
2 & $89 \mathrm{a}$ & $81 \mathrm{a}$ \\
3 & $83 \mathrm{~b}$ & $80 \mathrm{ab}$ \\
4 & $77 \mathrm{~d}$ & $78 \mathrm{bc}$ \\
5 & $75 \mathrm{~d}$ & $79 \mathrm{ab}$ \\
6 & $76 \mathrm{~d}$ & $71 \mathrm{de}$ \\
7 & $82 \mathrm{bc}$ & $79 \mathrm{ab}$ \\
8 & $80 \mathrm{c}$ & $76 \mathrm{c}$ \\
9 & $67 \mathrm{f}$ & $72 \mathrm{~d}$ \\
10 & $69 \mathrm{ef}$ & $69 \mathrm{e}$ \\
11 & $70 \mathrm{e}$ & $71 \mathrm{de}$ \\
12 & $64 \mathrm{~g}$ & $60 \mathrm{f}$ \\
\hline Range & $60 \mathrm{~h}$ & $56 \mathrm{~g}$ \\
\hline
\end{tabular}

Table 4. Correlation coefficients calculated for MGT, AA24h and 48h (Accelerated ageing) tests. electrical conductivity after 8h (EC8h), 16h (EC16h), 24h (EC24h), radicle emergence after 18 (RE18h), 24 (RE24h), 36h (RE36h), and 48h (EC48h) and standard laboratory germination (SG) as estimation of seedling emergence percentages of field emergence and controlled room conditions in rocket seed lots.

\begin{tabular}{|c|c|c|c|c|c|}
\hline \multirow[b]{2}{*}{ Seed Vigour Test } & \multicolumn{2}{|c|}{ Field Emergence } & \multicolumn{3}{|c|}{ Total } \\
\hline & 1. Sowing & 2. Sowing & $*$ & $* *$ & $* * *$ \\
\hline MGT & $-0.818^{* *}$ & $-0.877 * * *$ & & 1 & 1 \\
\hline AA24h & $0.822 * *$ & $0.813^{* *}$ & & 2 & 0 \\
\hline AA $48 \mathrm{~h}$ & $0.770 * *$ & $0.811^{* *}$ & & 2 & \\
\hline EC8h & $-0.798 * *$ & $-0.806^{* *}$ & & 2 & \\
\hline EC16h & $-0,830 * * *$ & $-0,820 * *$ & & 1 & 1 \\
\hline EC24h & $-0.824 * * *$ & $-0.844 * * *$ & & & 2 \\
\hline RE18h & $0.779 * *$ & $0.725^{* *}$ & & 2 & \\
\hline RE24h & $0.860 * * *$ & $\mathbf{0 . 8 7 4} * * *$ & & & 2 \\
\hline RE36h & $0.828 * * *$ & $0.898 * * *$ & & & 2 \\
\hline RE48h & $0.855 * * *$ & $0.908 * * *$ & & & 2 \\
\hline SG & $0.654 *$ & $0.640 *$ & 2 & & \\
\hline
\end{tabular}

$*: \mathrm{p}<0.05, * *: \mathrm{p}<0.01, * * *: \mathrm{p}<0.001$

The close correlations between EC24h, RE24h, SG and field emergence in two sowing times are well illustrated for 12 seed lots in figure 1. The variation in the field emergence percentages of twelve lots accounted for by regression and electrical conductivity readings after $24 \mathrm{~h}$ were $67 \%\left(R^{2}=0.67\right)$ in the first and $71 \%\left(R^{2}=0.71\right)$ in the second sowing. These values were slightly higher in RE24h as $74 \%$ $\left(R^{2}=0.74\right)$ and $76 \%\left(R^{2}=0.76\right)$, respectively. $R^{2}$ values for SG and field emergence was much lower. They were 0.42 and 0.41 in the first and second sowings, respectively. 

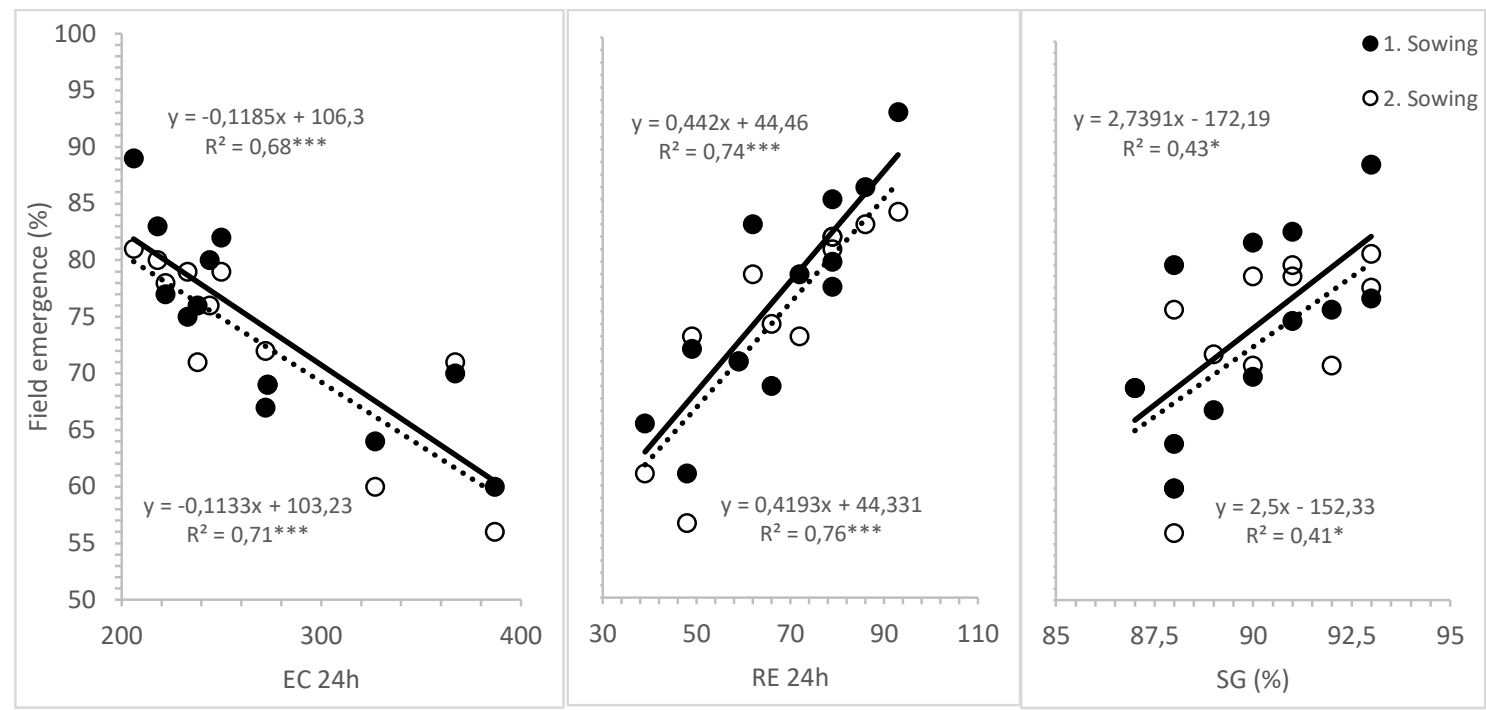

Figure 1. Relationship between electrical conductivity of $24 \mathrm{~h}$ (EC24h), radicle emergence of 24h (RE24h) and SG with field emergence in two sowings, of 1. (•) and 2. sowing (०) of 12 rocket seed lots. Significance: *: $0.05, * *: 0.01, * * *: 0.001$

The results of the present work indicated that electrical conductivity readings or radicle emergence percentages just after 24 hours were highly correlated to seedling emergence in two field sowing times $(p<0.001, r=0.824-0.874)$ in rocket seed lots. Seed vigour is considered as potential seedling emergence/stand establishment in the field or transplant modules particularly when the sowing environments are unoptimum or wide environmental ranges. TeKrony (2003) constituted the vigour as 'seed vigor is the sum of all those properties which determine the potential for rapid uniform emergence end development of normal seedlings under a wide range of field conditions'. Our results agreed with this definition since both vigour tests were correlated with seedling emergence in two different sowing times which possess different environments (Table 4). The possible persistence of the effects of seed vigor throughout the plant development cycle beyond the emergence persisting until yield is not valid for all species. The effect of seed vigor on yield in leafy vegetable species such as rocket is likely to occur. Rocket needs just 35-40 days of harvest period. It is well established finding that earlier emergence is the one of the main influence of vigor and fast germinators produce larger seedlings (Demir et al., 2008) during vegetative growth stage. The fast emergence and early covering the surface of the soil (better stand establishment) may also help to combat the weeds invasion in the field. Earlier emergence may also help seeds overcome soil diseases attack during the germination period. Because the longer the seeds remain ungerminated in the soil is the more likely to get attacked by soil diseases or pests. Attack by diseases and hindering seed emergence in the soil may be promoted by imbibitional chilling injury (Bedi and Basra, 1993).

Mc Donald (1999) described the ideal seed vigor tests as repeatable, fast and uniformly applicable amongst the laboratories. In this work we found the most optimum seed vigor tests as electrical conductivity and radicle emergence measured after 24 hours. In both tests results can be obtained within a day. EC test has been used in legumes and indicates membrane integrity which influenced by seed deterioration. It was used to identify the differences in vigour as reflected in field emergence in commercial seed lots of soybean, beans and chickpea (Powell et al., 1986; Khajeh-Hosseini and Razazedeh, 2011; Usha and Dadlani, 2015; Ozden et al., 2019). Aside from legumes EC test was used as a predictor of seedling emergence in the field such as radish (Mavi et al., 2014; Demir et al., 2019). Our results agreed in these findings that EC was highly related to seedling emergence. The highest 
correlation was found in EC24 h which is better than EC 16h and EC8h. In an earlier work, on EC measurements just after 2 hours was found to be an indicator of seed vigour in chickpea (KhajehHosseini and Rezazedeh, 2011). In our work even though earlier EC measurements were also found significant $(p<0.001), E C 24 h$ gave higher correlations than earlier readings $(p<0.001, r=0.824-0.844)$. That shows that longer time of soaking does help to discriminate the lots in better way due to the wider range of conductivity values. In that sense our results agreed with $24 \mathrm{~h}$ of soaking time of suggestion for legumes by ISTA (2017). However, great majority of solutes more than $50 \%$ leaked in an early hours of soaking, the first 8 hours, which indicates membrane damage (Table 2). While differences in EC readings of the lots in earlier times ( 8 hours) identified the same differences among the lots in later times (24 h). For example, the lowest leakage was observed in lot 1 as $131 \mu \mathrm{S} \mathrm{cm} \mathrm{g}^{-1}$ after 8 hours corresponding value was $206 \mu \mathrm{S} \mathrm{cm}^{-1} \mathrm{~g}^{-1}$ which was the lowest of all lots after $24 \mathrm{~h}$ (Table 2).

RE test has been found applicable to predict seedling emergence in various crops (Matthews and Powell, 2011). RE is validated as a vigour test to indicate field emeregence in maize and oilseed rape (ISTA, 2017), radish (Powell and Mavi, 2016), forage species (Lv et al., 2016), cress (Demir et al., 2019), bean (Ozden et al., 2019). Slower germination and lower RE values were also associated with seed ageing during storage (Ozden et al., 2017). In an earlier work (Matthews and Khajeh-Hosseini, 2007) the time from start of imbibition and radicle emergence in early stage of germination (lag period) is determined by the ageing level of the seed. They described that lag period as the time needed for repair of previously sustained deterioration as a results of ageing. Evidence of occurrence of ageing and repair hypothesis has been discussed with a comparison of various seeds (Powell and Matthews, 2012).

\section{CONCLUSION}

As a conclusion the rate of radicle emergence percentages and electrical conductivity readings offer succesful possibility to gain vigour potential of rocket seed lots in relation to seedling emergence. Both tests are uncomplicated, easy, rapid, particularly convenient for small number of seed lots in small laboratories. Further work is needed wider potential of these approaches to predict the potential seedling emergence of seed lots in different specis.

\section{REFERENCES}

Abd El-Hamid SR, 1999. Biochemical studies on some untraditional plant oils. M.Sc. Thesis. Biochemistry department. Faculty of Sciences. Ain-Shams University, pp 40.

Basak O, Demir I, Mavi K, Matthews S, 2006. Controlled deterioration test for predicting seedling emergence and longevity of pepper (Capsicum annuum L.) seed lots. Seed Science and Technology, 34: 723-734.

Bedi S, Basra AS, 1993. Chilling injury in germinating seeds: basic mechanisms and agricultural implications. Seed Science Research, 3: 219-229.

Demir I, Ermis S, Mavi K, Matthews S, 2008. Mean germination time of pepper seed lots (Capsicum аппиит) predicts size and uniformity of seedlings in germination tests and transplant modules. Seed Science and Technology, 36: 21-30.

Demir I, Kenanoglu BB, Ozden E, 2019. Seed Vigour Tests to Estimate Seedling Emergence in Cress (Lepidium sativum L.) Seed Lots. Notulae Botanicae Horti Agrobotanici Cluj-Napoca, 47(3): 881886.

Finch-Savage W, Clay HA, Lynn JR, Morris K, 2010. Towards a genetic understanding of seed vigour in small seeded crops using natural variaotaion in Brassica oleracea. Plant Science, 179: 582-589. 
Hampton, JG, Tekrony DM, 1995. Handbook of Vigor Test Methods, International Seed Testing Association, Bassersdorf, Switzerland.

ISTA, 2017. International Rules for Seed Testing, International Seed Testing Association, Bassersdorf, Switzerland.

Khajeh-Hosseini M, Rezazadeh M, 2011. The electrical conductivity of soak-water of chikpea seeds provides a quick test indicative of field emergence. Seed Science and Technology, 39: 692-696.

Lv YY, Wang YR, Powell AA, 2016. Frequent individual counts of radicle emergence and mean just germination time predict seed vigour of Avena sativa and Elymus nutans. Seed Science and Technology, 44: 189-198.

Marcos-Filho M, 2015. Seed vigor testing: an overwiew of the pat, present and future perspectives. Scientia Agricola, 72: 363-374.

Matthews S, Powell AA, 2011. Towards automated single counts of radicle emergence to predict seed and seedling vigour. Seed Testing International, 142: 44-48.409.

Matthews S, Khajeh-Hosseini M, 2007. Length of the lag period of germination and metabolic repair explain vigour differences in seed lots of maize (Zea mays L.). Seed Science and Technology, 35: 200-212.

Mavi K, Mavi F, Demir I, Matthews S, 2014. Electrical conductivity of seed soak water predicts seedling emergence and seed storage potential in commercial seed lots of radish. Seed Science and Technology, 42: 76-86.

McDonald MB, 1999. Seed deterioration: physiology, repair and assesment. Seed Science and Technology, 27: 177-237.

Ozden E, Memis N, Kapcak D, Durmus E, Ozdamar C, Ozdemir M, Demir I, 2017. Electrical conductivity relates seed germination in cress. 2nd International Balkan Agriculture Congress, Tekirdag, Turkey, May 16-18, 2017, pp. 476-481.

Ozden E, Memis N, Gokdas Z, Catikkas E, Demir I, 2019. Evaluation of Seed Vigour in White Coat French Bean (Phaseolus vulgaris L.) Seed Lots Under Waterlogged or Field Capacity Conditions. Journal of the Institute of Science and Technology, 9(4): 1860-1865.

Powell AA, Oliveira M De A, Matthews S, 1986. Seed vigor in cultivars of dwarf French bean (Phaseolus vulgaris) in relation to the colour of the testa. Journal of Agricultural Science, 106: 419-425.

Powell AA, Matthews S, 2012. Seed aging/repair hypothesis leads to new testing methods. Seed Technology, 34: 15-25.

Powell AA, Mavi K, 2016. Application of the radicle emergence test to radish (Raphanus sativus) seed. In Method Validation Reports 2016, pp. 65-72, International Seed Testing Association, Bassersdorf. Method-Validation-Reports-for-Rules.

Usha TS, Dadlani M, 2015. Evaluation of seed vigor in soybean (Glycine max). Legume Research, 38(3): 308-312. 